\title{
A PANEL DATA MODEL OF INTERNATIONAL TOURISM DEMAND FOR GREECE
}

\author{
Athanasia MAVROMMATI ${ }^{\mathrm{a}}$, Konstantina PENDARAKI ${ }^{\mathrm{a}}$, Achilleas \\ KONTOGEORGOS ${ }^{\mathrm{b}}$, Fotios CHATZITHEODORIDIS ${ }^{\mathrm{c}^{*}}$
}

\footnotetext{
${ }^{a}$ University of Patras, Department of Business Administration of Food and Agricultural Enterprises, amavrom@upatras.gr and dpendara@upatras.gr

b International Hellenic University, Department of Agriculture, akontoge@ihu.gr

$c^{*}$ University of Western Macedonia, Department of Regional and Cross-Border Development, fxtheodoridis@uowm.gr
}

Cite this article: Mavrommarti, A., Pendaraki, K., Kontogeorgos, A., Chatzitheodoridis, F. (2021). A Panel Data Model of International Tourism Demand for Greece. Deturope. 13(3), 142-157.

\begin{abstract}
Tourism is an important industry which affects the profits of national economy. A strong tourism sector directly contributes to the national income of the country, combats unemployment and improves the balance of payments. Tourism demand is usually measured by the number of tourist visits from an origin country to a destination country, in terms of tourist nights spent in the destination country or in terms of tourist expenditures by visitors from an origin country to the destination country. The purpose of this study is to investigate the determinants of international tourism demand for Greece and to quantify their influences. Four econometric models have been developed with different combinations of countries, to estimate tourist inflow data from twenty-eight European and non-European countries, for the period 1996-2015. Various potential determinants are investigated, including gross domestic product, currency, the average per capita tourism expenditure and the marketing expenses to promote tourism industry. The empirical results indicate that the explanatory variables affect the tourism demand of Greece and play an important role in strategies that affect total cost, demand, and structure of the Greek tourism market.
\end{abstract}

Keywords: International tourism demand, Greece, panel data analysis, modelling

\section{INTRODUCTION}

Tourism is an important industry which affects the profits of national economies. According to the annal analysis of the World Travel \& Tourism Council (WTTC, 2019), the tourism activity in Greece generates about $20.8 \%$ of the gross domestic product, represents $21.7 \%$ of the total employment and contributes decisively to attenuate the current account deficit of the balance of payments. These numbers show that tourism industry is rapidly growing in contrast to other sectors of the Greek economy and become one of the major factors of socio-economic progress through the generation of jobs, the strengthening of export income and the enforcement of infrastructure development (Kolokontes et al., 2018). 
Greece is one of the world's major tourist destinations. The difficult economic situation in Greece and the instability due to the pandemic appear to have affected the country's tourism industry (Chatzitheodoridis \& Kontogeorgos, 2020). The arrivals have been affected by the impact of the coronavirus (Covid-19) pandemic and Greece's tourism revenue dropped by $77 \%$ during the 2020. According to the Bank of Greece, travel receipts from January to October of 2020 were down to only some 4 billion euros compared to 13.5 billion euros in the corresponding period of 2019. Furthermore, during the first ten months of 2020, visitor flows through airports declined by $72.8 \%$ and arrivals through road border-crossing points were down by $83.4 \%$.

A better knowledge of the factors that explain the tourists' preferences to choose Greece as a destination place will help the policy makers to design more adequate strategies to develop further this sector. Therefore, it is essential to analyse determinants of the Greek tourism demand, in order for the tourism industry to apply efficient management and to correspond to infrastructure development needs. Tourism demand forecasting would help managers and investors make operational, efficient and strategic decisions. The substantial contribution of tourism in the Greek economy justifies the interest in explaining the determinants of tourism demand and, therefore, the factors which influence the decision of tourists to choose the country as a destination place.

The present study analyses empirically the determinants of tourism demand in Greece through four econometric models for a statistically significant sample of twenty-eight European and non-European countries for the years 1996-2015. The depended variable in all models is the number of visitors (VIS), while the explanatory variables are: The Gross Domestic Product per capita (GDP) by country, the marketing expenses to promote Greek tourism industry in each foreign country (ADV), the average per capita tourism expenditure in Greece by country (EXP), the population in foreign countries (POP) and the foreign exchange rate (FER) expressed in US dollars. To our knowledge, there is no other research work that has used the advertising expenses of Greece in tourism origin countries as an explanatory variable.

More specifically, the first model investigates the determinants of tourism demand in Greece for eleven European countries with different currencies for the period 1996-2015 and includes all the explanatory variables. The second model investigates the determinants of tourism demand in Greece for eleven European countries with the same currency for the period 19962015 and excludes the exchange rate (FER) from the explanatory variables. The third model analyses the determinants of tourism demand in Greece for sixteen European and non-European countries with different currencies for the period 1996-2015, includes all the explanatory 
variables, but excludes USA because the currency is expressed in US dollars. The fourth and last model analyses the determinants of tourism demand in Greece for twenty-eight European and non-European countries for the period 1996-2015 and excludes the exchange rate (FER) from the explanatory variables.

Section 2 presents the literature review, while the rest of the paper is organized as follows: section three presents the model specification and the data set. The methodological framework is presented in section four. Empirical results are discussed in section five and conclusions are summarised in the last section.

\section{THEORETICAL BACKGROUND}

The growth of both the world-wide tourism industry and academic interest in tourism over the last years has generated great interest in tourism demand modelling in both the business and the academic area. Tourism demand modelling research relies heavily on secondary data in terms of model construction and estimation. International tourism demand models use tourist arrivals and expenditures as the most frequent dependent variables (Lim, 1997; Song \& Li, 2008). Numerous studies have shown that forecasting tourism demand remains important in order to predict the future of tourism (Brand, 1973; Chan, 1979; Vanhove, 1980; Sheldon \& Var, 1985; Crouch, 1994; Witt \& Witt, 1995; Lim, 1997a, 1997b and 1999; Li et al., 2005; Song \& Li, 2008; Karlaftis, 2010; Goh \& Law, 2011; Moro, et al., 2017; Khaidi et al., 2019; Ghalehkhondabi et al., 2019). These review studies categorize demand models and methods into three main approaches: time-series, econometric and artificial intelligence models.

Time-series models have been broadly applied because they provide simplicity in data collection, cost effectiveness in the application and interpretation of forecasting demand and allow comparisons for benchmarking purposes (Andrew et al., 1990; Goh \& Law, 2002; Cho, 2003; Chan et al., 2005; Coshall, 2006; Adhikari \& Agrawal, 2012; Baldigara \& Mamula, 2015; Tang, et al., 2015). Econometric models, on the other hand, enrich the study of forecasting tourism demand by linking the causal relationship between tourism demand and its influencing factors (Clements \& Hendry, 1998; Lathiras \& Siriopoulos, 1998; Kulendran \& Wilson, 2000; Song \& Witt, 2003; Lim \& McAleer, 2001; Turner \& Witt, 2001, Dritsakis, 2004; Song \& Wong, 2003; Algieri, 2006; Han et al., 2006). More specifically, panel data approach provides researchers with massive data sets, increases the degree of freedom, reduces the collinearity among explanatory variables, and improves efficiency of econometric estimation (Serra et al., 2014). Most recent studies that use panel data have examined both economic and non-economic 
factors that affect international tourism demand. Moreover, artificial intelligence is recently introduced by the emergence of programming systems in analyzing and predicting tourism demand (Kon \& Turner, 2005; Li et al., 2006; Palmer et al., 2006; Claveria \& Torra 2014; Cankurt \& Subasi, 2016; Karakitsiou \& Mavrommati, 2017). Nevertheless, econometric models overtake both time-series and artificial models in predicting tourism demand, given their advantage in linking the dependent variable with its explanatory ones (Khaidi et al., 2019).

International tourism demand models use most frequently tourist arrivals/departures and expenditures/receipts as the dependent variables (Kulendran \& Wong, 2005; Coshall, 2005; Rosselló, 2001; Tang, et al., 2015; Cankurt \& Subasi, 2016; Rafidah, et al., 2017), while there also a few studies which measure the number of overnight stays such as these of Claveria \& Torra (2014) and Constantino et al. (2016). The most common explanatory variables used, are the real gross domestic product for approaching the tourist incomes, the consumer price index, the tourism cost of the destination country relative to the country of origin, the exchange rate, the living cost, as well as the price of the competing destination (Song et al., 2003, Constantinino et al., 2016; Song et al., 2011; Cankurt et al., 2015; Gunter, 2015; Zhu, et al., 2018; Assaf et al., 2019). Country of origin (Claveria \& Torra, 2014) and allowance for visitors (Liang, 2014) are also chosen as explanatory variables in certain studies. Also, some researchers use tourism related keywords from search engines (Liang, 2014; Yang et al., 2015; Önder 2017; Kirilenko \& Stepchenkova, 2018). Other determinant variables are also considered, like distance or transportation costs (Lim \& McAleer, 2001; Muhammad \& Andrews, 2008; Hanafiah \& Harun, 2010), population (Hanafiah \& Harun, 2010), tourism infrastructure as accommodation capacity (Seetanah, 2006), consumer tastes or fashion (Song \& Witt, 2000).

\section{Model Specifications and Variable Definition}

The demand of tourism in Greece by tourists from European and non-European countries is analyzed by four different panel data sets. The panel data sets consist of tourist arrivals of twenty-eight countries, namely the UK, Switzerland, Czech Republic, Sweden, Bulgaria, Denmark, Hungary, Norway, Poland, Romania, Russia, USA, Turkey, Australia, Canada, Japan, Israel, Austria, Cyprus, Italy, France, Spain, Slovakia, Germany, Netherlands, Portugal, Finland, and Ireland. Based on a sample period of 20 years, from 1996 to 2015, the data for the study are obtained from the World Bank Reports, the World Travel and Tourism Council, the European Central Bank Statistical Data, Media Services S.A., the Greek Research Institute of Tourism and the Bank of Greece. 
The dependent variable is the number of visitors in Greece from the origin country (VIS), since it is the most widely used variable in studies on tourism demand (Tang, et al., 2015; Cankurt \& Subasi, 2016; Rafidah, et al., 2017). Five explanatory variables have been used to measure the influence on tourism demand (VIS) in the current model. The Gross Domestic Product per capita (GDP) in each country, as a measure variable for analysing income, has a positive impact on tourism arrivals (Surugiu, Leitão, \& Surugiu, 2011; Deng \& Athanasopoulos, 2011). The exchange rate (FER) between the destination country and origin countries is expressed in US dollars and measures the effective prices of goods and services in the destination country, in relative to origin countries. It is an indicator of purchasing power of tourists in Greece and has a positive impact on tourism arrivals (Kulendran \& Wilson 2000; Chinnakum \& Boonyasana 2017). The average per capita tourism expenditure in each country (EXP), being a representative of the component cost of travel to the destination, negatively influences the tourist arrivals (Au \& Law, 2002; Brida \& Risso, 2009). The population in each country (POP) positively affects tourism demand (Oigenblick \& Kirschenbaum, 2002). The current study is further enhanced by the inclusion of an important variable in the model, which is related to the tourism advertising expense in each country (ADV) as a representative of tourism marketing. Tourism advertising expense has been suggested by Chinnakum and Boonyasana (2017) as an explanatory variable, which has not been broadly studied yet in the tourism demand forecasting models.

The following theoretical model is used in order to estimate international tourism demand towards Greece and is applied to four different data sets from twenty-eight European and nonEuropean countries:

$V I S_{i t}=c_{i}+b_{1} G D P+b_{2} A D V+b_{3} P O P+b_{4} E X P+b_{5} F E R+u_{i t}$, where i refers to cross sections and t refers to time periods.

VIS is the number of tourist arrivals from country of origin to Greece

GDP is the Gross Domestic Product per capita of country of origin

ADV is the marketing expenses to promote Greek tourism industry in the country of origin

POP is the population in the country of origin

EXP is the average per capita tourism expenditure of tourists in the host country

FER is the bilateral exchange rate between Greece and the country of origin

In this study, due to data unavailability, EXP and FER were used as a proxy for the cost of living for tourists in Greece and ADV was used as a proxy for marketing expenses to promote 
Greek tourism industry. Similarly, GDP was used as a proxy for the income level of foreign tourists. All monetary values are measured in US dollars.

Four panel data sets are analyzed, categorizing the countries by their geographical position and by their currency. The first data set studies the determinants of tourism demand in Greece for eleven European countries with different currencies, for the period 1996-2015. This model includes all the explanatory variables for the following countries: the UK, Switzerland, the Czech Republic, Sweden, Bulgaria, Denmark, Hungary, Norway, Poland, Romania and Russia. The second data set studies the determinants of tourism demand in Greece for eleven European countries with the same currency, for the period 1996-2015. This model excludes from the explanatory variables the exchange rate (FER) and is applied for the following countries: Austria, Cyprus, Italy, France, Spain, Slovakia, Germany, the Netherlands, Portugal, Finland and Ireland. The third data set studies the determinants of tourism demand in Greece for sixteen European and non-European countries with different currencies, for the period 1996-2015. This model includes all the explanatory variables but excludes USA because the currency is expressed in US dollars and is applied for: the UK, Switzerland, the Czech Republic, Sweden, Bulgaria, Denmark, Hungary, Norway, Poland, Romania, Russia, Turkey, Australia, Canada, Japan and Israel. The fourth and last model studies the determinants of tourism demand in Greece for twenty eight European and non-European countries for the period 1996-2015, excludes the exchange rate (FER) from the explanatory variables and is applied for the following countries: the UK, Switzerland, the Czech Republic, Sweden, Bulgaria, Denmark, Hungary, Norway, Poland, Romania, Russia, USA, Turkey, Australia, Canada, Japan, Israel, Austria, Cyprus, Italy, France, Spain, Slovakia, Germany, the Netherlands, Portugal, Finland and Ireland.

\section{DATA AND METHODS}

As far as tourism demand is concerned, econometric analysis has its empirical usefulness in interpreting the change of tourism demand and evaluating the effectiveness of the existing tourism policies. Panel data models consider the cross sectional and time series properties of the data, for example, tourism revenue observed by origin and over time. In the present study, the term "panel data" refers to the pooling of observations in a cross-section of the eleven selected countries over a period of twenty years (1996-2015) and the data used were obtained from the following sources: World Bank Reports; World Travel and Tourism Council; 
European Central Bank, Statistical Data; Media Services S.A.; Research Institute of Tourism; Bank of Greece.

The combination of cross section and time series data should be conducted in an appropriate statistical way, otherwise the coefficients will not be efficient. A variety of estimation techniques for panel data models have been developed in the literature that enable relaxation of many of the restrictive assumptions of the single cross-sectional stochastic model and give rise to alternative measures of efficiency. These include the fixed effects model and the least squares dummy variable (LSDV) estimation, the random effects model and the generalised least squares (GLS) estimation and finally, maximum likelihood estimation (MLE).

The fixed effect model explores the relationship between predictor and outcome variables within an entity (country, company, etc.). Each entity has its own individual characteristics that may or may not influence the predictor variables. The model requires relatively weak assumptions and allows $\alpha_{i}$ (i.e., the unknown intercept for each entity) to differ across the crosssection units, and the estimates for the constants are different for each cross section. It provides a convenient means of allowing for differences in coefficients, which may occur for different samples or for different sample distributions (Carter at al., 1988). That is,

$$
Y_{i t}=\sum_{z=1}^{Z} \beta_{z} X_{i t}+\alpha_{i}+u_{i t}
$$

with $\mathrm{i}=1 \ldots \mathrm{Z}$ and $\mathrm{t}=1 \ldots \mathrm{T}$,

where $Y_{\text {it }}$ represents the value of the dependent variable for entity $i$ at time $t, X_{i t}$ is the value of any $\mathrm{Z}$ explanatory variable for entity $i$ at time $t$, and $u_{i t}$ is the error term with the standard assumption, $\beta_{\mathrm{z}}$ is the coefficient for the explanatory variables and $\alpha_{i}$ is the unknown intercept for each entity. The fixed effects model is a classical regression model and controls all timeinvariant differences between the entities, so the estimated coefficients of the fixed-effects models cannot be biased because of omitted time-invariant characteristics.

The rationale behind the random effects model is that, unlike the fixed effects model, the variation across entities is assumed to be random and uncorrelated with the predictor or independent variables included in the model. More specifically, the random effects model assumes that the term $\alpha_{i t}$ is the sum of a common constant $\alpha$ and a time-invariant cross section specific random variable $u_{i}$ that is uncorrelated with the disturbance term $\varepsilon_{i t}$. This means that,

$$
Y_{i t}=\sum_{z=1}^{Z} \beta_{z} X_{i t}+\alpha_{i t}+u_{i t}+\varepsilon_{i t}
$$

where $\mathrm{E}[\mathrm{u}(\mathrm{i})]=0, \operatorname{Var}[\mathrm{u}(\mathrm{i})]=\sigma^{2}(\mathrm{u}), \operatorname{Cov}[\varepsilon(\mathrm{i}, \mathrm{t}), \mathrm{u}(\mathrm{i})]=0$. 
The random effects model is a generalized regression model. All disturbances have a variance of $\operatorname{Var}[\varepsilon(\mathrm{i}, \mathrm{t})+\mathrm{u}(\mathrm{i})]=\sigma^{2}=\sigma^{2}(\varepsilon)+\sigma^{2}(\mathrm{u})$.

For a given i, the disturbances in different periods are correlated because of their common component, $u(i), \operatorname{Corr}[\varepsilon(i, t)+u(i), \varepsilon(i, t)+u(i)]=\rho=\sigma^{2}(u) / \sigma^{2}$.

Random effects assume that the entity's error term is not correlated with the predictors, which allows for time-invariant variables to play a role as explanatory variables and the efficient estimator is the generalized least square.

Each one of the above methods of estimation makes different assumptions about the distribution of technical efficiency and its potential correlation with the regressors. If observations on statistical noise, as well as on firm effects, are assumed independent over time and across entities, following a specific distribution, then the stochastic frontier specification is not different from the maximum likelihood estimates of the panel model [Madalla (1991, 1987)]. In order to decide between fixed or random effects we run a Hausman test where the null hypothesis is that the preferred model is random effects vs. the alternative fixed effects.

\section{RESULTS AND DISCUSSION}

The model constructed in this study is based on the classical economic theory which assumes that income, cost of living, advertising expenses and price factors play an important role in determining the international demand for tourism. Given the model and data in which fixedeffects estimation would be appropriate, Hausman-test tests whether random-effects estimation would be almost as good. The application of the Hausman-test for fixed effects or random effects in our study shows that the fixed effect model is the advisable estimation method for the model.

The regression results of pooled OLS and fixed effect estimator are shown in Table 1 and give the estimated coefficients for the first panel data set of eleven European countries with different currencies. The explanatory power of the Greek tourism demand regression is quite high (R-squared=0.68). According to the results displayed, all of the variables have the expected signs and most of the variables have the expected level of significance. A series of t-test at $1 \%$ and 5\% level of significance have been applied on each independent variable against the dependent variable. From the above panel model equation, EXP, POP, FER share the same level of significance, which is $1 \%$. ADV is statistically significant at $5 \%$. Just GDP was nonsignificant. 
Table 1 Pooled OLS regression/Fixed Effect model estimation of the tourism demandEuropean countries with different currencies - (1996-2015)

\begin{tabular}{lcccc}
\hline \hline & \multicolumn{2}{c}{ OLS Regression } & \multicolumn{2}{c}{ Fixed Effect Model } \\
\hline \hline & Coefficient & Prob.- Value & Coefficient & Prob.- Value \\
C (constant) & 456072.1 & 0.000 & 366788.9 & 0.000 \\
GDP & 5.189628 & 0.051 & 4.590813 & 0.056 \\
ADV & 0.0010547 & 0.049 & 0.0007149 & 0.045 \\
EXP & -566.6471 & 0.000 & -405.7309 & 0.000 \\
POP & 0.0051583 & 0.000 & 0.0050424 & 0.003 \\
FER & 399092.70 & 0.000 & 456535.10 & 0.000 \\
Observations & 220 & & 220 & \\
\hline \hline & $\mathrm{R}^{2}$ & 0.70 & R-sq (overall) & 0.68 \\
& $\mathrm{R}^{2}$ Adjusted & 0.69 & F (5, 204) & 18.16 \\
& F-Statistic & 0.99 & Prob $>$ F & 0.000 \\
& & & rho & 0.8486
\end{tabular}

Countries: UK, Switzerland, Czech Republic, Sweden, Bulgaria, Denmark, Hungary, Norway, Poland, Romania, Russia

Source: Authors' own work.

The regression results of pooled OLS and fixed effect estimator are shown in Table 2 and give the estimated coefficients for the second panel data set of eleven European countries with same currencies. The explanatory power of the Greek tourism demand regression is quite high (R-squared $=0.67$ ). According to the results displayed, most of the variables have the expected signs and the expected levels of significance. A series of t-test at $1 \%$ and $5 \%$ levels of significance have been applied on each independent variable against the dependent variable. From the above panel model equation, POP is statistically significant at $1 \%$. ADV and EXP are statistically significant at 5\%. Just GDP was non-significant.

Table 2 Pooled OLS regression/Fixed Effect model estimation of the tourism demandEuropean countries with the same currency - (1996-2015)

\begin{tabular}{lcccc}
\hline \hline & \multicolumn{2}{c}{ OLS Regression } & \multicolumn{2}{c}{ Fixed Effect Model } \\
\hline \hline & Coefficient & Prob.- Value & Coefficient & Prob.- Value \\
C (constant) & 326092.8 & 0.035 & 365954.5 & 0.043 \\
GDP & 3.82788 & 0.051 & 2.62621 & 0.052 \\
ADV & 0.004952 & 0.016 & 0.005194 & 0.019 \\
EXP & -178.0669 & 0.037 & -176.9718 & 0.038 \\
POP & 0.023903 & 0.000 & 0.0482678 & 0.000 \\
Observations & 220 & & 220 & \\
\hline \hline & $\mathrm{R}^{2}$ & 0.69 & R-sq (overall) & 0.67 \\
& $\mathrm{R}^{2}$ Adjusted & 0.67 & F (4, 205) & 21.70 \\
& F-Statistic & 0.98 & Prob $>$ F & 0.000 \\
& & & rho & 0.9250
\end{tabular}

Countries: Austria, Cyprus, Italy, France, Spain, Slovakia, Germany, Netherlands, Portugal, Finland, Ireland

Source: Authors' own work. 
The regression results of pooled OLS and fixed effect estimator are shown in Table 3 and give the estimated coefficients for the third panel data set of sixteen European and non-European countries with different currencies. The explanatory power of the Greek tourism demand regression is quite high ( $\mathrm{R}$-squared=0.69). According to the results displayed, most of the variables have the expect sign and level of significance. A series of t-test at $1 \%$ and $5 \%$ levels of significance have been applied on each independent variable against the dependent variable. From the above panel model equation, EXP, POP, FER share the same significant level of $1 \%$. ADV, GDP are significant at 5\%.

Table 3 Pooled OLS regression/Fixed Effect model estimation of the tourism demandEuropean and non-European countries with different currencies - (1996-2015)

\begin{tabular}{lcccc}
\hline \hline & \multicolumn{2}{c}{ OLS Regression } & \multicolumn{2}{c}{ Fixed Effect Model } \\
\hline \hline & Coefficient & Prob.- Value & Coefficient & Prob.- Value \\
C (constant) & 302898.1 & 0.000 & 423182.4 & 0.043 \\
GDP & 1.637921 & 0.042 & 5.282839 & 0.012 \\
ADV & 0.007893 & 0.013 & 0.003858 & 0.015 \\
EXP & -359.4124 & 0.000 & -244.8359 & 0.000 \\
POP & 0.0023657 & 0.000 & 0.0221498 & 0.002 \\
FER & 683058.9 & 0.000 & 126280.7 & 0.030 \\
Observations & 320 & & 320 & \\
\hline \hline & $\mathrm{R}^{2}$ & 0.71 & R-sq (overall) & 0.69 \\
& $\mathrm{R}^{2}$ Adjusted & 0.67 & F (5, 299) & 18.88 \\
& F-Statistic & 0.92 & Prob $>$ F & 0.000 \\
& & & rho & 0.8013
\end{tabular}

Countries: UK, Switzerland, Czech Republic, Sweden, Bulgaria, Denmark, Hungary, Norway, Poland, Romania, Russia, Turkey, Australia, Canada, Japan, Israel

Source: Authors' own work.

The regression results of pooled OLS and fixed effect estimator are shown in Table 4 and give the estimated coefficients for the fourth panel data set of twenty-eight European and nonEuropean countries with different currencies. The explanatory power of the Greek tourism demand regression is quite high ( $\mathrm{R}$-squared $=0.70)$. According to the results displayed, most of the variables have the expect signs and levels of significance. A series of t-test at $1 \%$ and $5 \%$ levels of significance have been applied on each independent variable against the dependent variable. From the above panel model equation, EXP, GDP share the same level of significance of $1 \%$. ADV and POP are significant at $5 \%$. 
Table 4. Pooled OLS regression/Fixed Effect model estimation of the tourism demand-All countries - (1996-2015)

\begin{tabular}{|c|c|c|c|c|}
\hline & \multicolumn{2}{|c|}{ OLS Regression } & \multicolumn{2}{|c|}{ Fixed Effect Model } \\
\hline & Coefficient & Prob.- Value & Coefficient & Prob.- Value \\
\hline $\mathrm{C}$ (constant) & 172019.1 & 0.016 & 20798.6 & 0.024 \\
\hline GDP & 6.882554 & 0.000 & 6.189788 & 0.000 \\
\hline $\mathrm{ADV}$ & 0.003485 & 0.041 & 0.003429 & 0.045 \\
\hline EXP & -173.0059 & 0.000 & -168.988 & 0.000 \\
\hline POP & 0.004508 & 0.002 & 0.0095362 & 0.000 \\
\hline Observations & 560 & & 560 & \\
\hline & $\begin{array}{l}\mathrm{R}^{2} \\
\mathrm{R}^{2} \text { Adjusted } \\
\text { F-Statistic }\end{array}$ & $\begin{array}{l}0.72 \\
0.68 \\
0.92\end{array}$ & $\begin{array}{l}\text { R-sq (overall) } \\
\text { F }(5,528) \\
\text { Prob }>\text { F } \\
\text { rho }\end{array}$ & $\begin{array}{c}0.70 \\
20.88 \\
0.000 \\
0.8613\end{array}$ \\
\hline \multicolumn{5}{|c|}{$\begin{array}{l}\text { Countries: UK, Switzerland, Czech Republic, Sweden, Bulgaria, Denmark, Hungary, Norway, } \\
\text { Poland, Romania, Russia, USA, Turkey, Australia, Canada, Japan, Israel, Austria, Cyprus, } \\
\text { Italy, France, Spain, Slovakia, Germany, Netherlands, Portugal, Finland, Ireland }\end{array}$} \\
\hline
\end{tabular}

As was expected, FER has a significant positive effect on tourism arrivals in Greece (Kulendran \& Wilson 2000; Chinnakum \& Boonyasana 2017), therefore an increase in foreign exchange rate would increase tourism arrivals. However, the EXP variable has a significant negative impact in the model as expected (Au \& Law, 2002; Brida \& Risso, 2009), therefore an increase in journey expenses in the host country would reduce tourism arrivals. Hence, it is concluded that prices do affect arrivals in a negative way. According to the findings of previous research (Surugiu, Leitão, \& Surugiu, 2011; Deng \& Athanasopoulos, 2011) the GDP variable had a positive impact on tourism arrivals, as well as the population (POP) (Oigenblick \& Kirschenbaum, 2002). The higher the income per capita, the higher the tourism arrivals are. The higher the population in origin countries, the higher the tourism demand for Greece. Advertising expenses have also shown a significant relationship in increasing tourism demand (Song \& Jiang, 2019). An increase in promotion expenses in countries of origin would increase tourism arrivals in Greece.

\section{CONCLUSION}

The Tourism sector is an important sector in terms of contribution to growth and profitability in all countries. This study examines the effects of structural and performance variables on tourism demand, taking into consideration the component cost of travel to the destination, the income per capita, the population and the travel expenses, among others. The most important contribution of the current research is the study of the tourism advertising expense as an impact factor to international tourism demand for Greece. In order to measure tourism, demand we 
used four constructed panel databases for European and non-European countries for the period 1996-2015.

Important economic factors such as gross domestic product, price, advertising expenses for promotion, exchange rate and the population number have been studied as independent variables in the model. The empirical results indicate that international tourist arrivals to Greece are positively determined by GDP per capita (GDP), advertising expenses (ADV), exchange rate (FER) and population (POP), while relative price (EXP) has a negative impact on international tourist arrivals to Greece. Panel data using fixed-effects model results, suggested that $70 \%$ of the variation in twenty-eight European and non-European countries tourist inflows, could be explained by real income per capita, advertising expenses, population and prices. All the independent variables were significant in the panel data analysis model.

Based on our findings, income in the country of origin plays an important role in determining international tourist arrivals to Greece. International tourists consider tourism in Greece as a necessary goods and a valuable service. Our work also proves that tourism is very much dependent on the economic conditions of the countries of origin. Moreover, high values of income in the countries of origin mean that demand for travelling and vacation increases significantly. Therefore, Greece will benefit from the long run growth of income in other countries.

The advertising expenses in tourism industry is an information source that dynamically affects tourists' price decisions and spending (Song and Jiang, 2019). However, the impact of advertising expenditure on generating tourists' arrivals is difficult to be estimated and, therefore, countries seek to eliminate these costs. In addition to this, the different utility function faced by different consumers displays different behaviours in choosing and purchasing tourist products. Effective advertising might be, therefore, the answer to this tricky equation.

In order to sustain tourist arrivals in Greece it is necessary to increase promotion and advertising expenses and reduce travel prices and the cost of living. It seems that although tourists are sensitive to prices and travel expenses, they are attracted by advertising and promotion when deciding to travel and choose a destination. The recent evolution of technology and social media in the last decades could be exploited by countries to generate arrivals with low-cost promotion campaigns. Marketing campaigns in the form of social media content affects the behaviour of tourists, as well as their decision making towards a destination. In this vein, the importance of advertising the tourist product can be supported by promoting tourism in less costly ways, such as social media campaigns. 


\section{REFERENCES}

Andrew, W.P., Crange, D.A., \& Lee, C.K. (1990). Forecasting hotel occupancy rates with time series models: A empirical analysis. Hospitality Research Journal, 14 (2), 173-181.

Adhikari, R., \& Agrawal, R.K. (2012). Forecasting strong seasonal time series with artificial neural networks. Journal of Scientific \& Industrial Research, 71, 657-666.

Algieri, B. (2006). An econometric estimation of the demand for tourism: the case of Russia. Tourism Economics, 12, 5-20.

Assaf, A. G., Li, G., Song, H., \& Tsionas, M.G. (2019). Modelling and forecasting regional tourism demand using the Bayesian Global Vector Autoregressive (BGVAR) Model. Journal of Travel Research, 58(3), 383-397.

$\mathrm{Au}, \mathrm{N} .$, \& Law, R. (2002). Categorical classification of tourism dining. Annals of Tourism Research, 29, 819-833.

Baldigara, T., \& Mamula M. (2015). Modelling international tourism demand using seasonal ARIMA models. Tourism and Hospitality Management, 21(1), 19-31.

Brand, D. (1973), Travel demand forecasting: some foundations and a review. Highway Research Board Special Report, No. 143, Williamsburg, VA.

Brida, J., \& Risso, W. (2009). A dynamic panel data study of the German demand for tourism in South Tryrol. Tourism and Hospitality Research, 9(4), 305-314.

Cankurt, S., \& Subasi, A. (2015). Developing tourism demand forecasting models using machine learning techniques with trend, seasonal and cyclic components. Balk Journal of Electrical and Computer Engineering, 3(1), 42-49.

Cankurt, S., \& Subasi, A. (2016). Tourism demand modelling and forecasting using data mining techniques in multivariate time series: a case study in Turkey. Turkish Journal of Electrical Engineering and Computer Sciences, 24(5), 3388-404.

Carter, H.R., Griffiths, W.E., Liitkepohl, H., \& Tsounh, C.L. (1988). Introduction to the theory and practice of econometrics (2nd edition), John Wiley, New York.

Chan, Y. (1979). Review and compilation of demand forecasting experiences: an aggregation of estimation procedures, Department of Transportation, No. DOT-P-30-80-25, Washington, DC.

Chan, F., Lim, C., \& McAleer, M. (2005). Modelling multivariate international tourism demand and volatility. Tourism Management, 26, 459-471.

Chatzitheodoridis, F., \& Kontogeorgos, A. (2020). Exploring of a Small-Scale Tourism Product under Economic Instability: The Case of a Greek Rural Border Area. Economies, 8 (3): 52. https://doi.org/10.3390/economies 8030052

Chinnakum, W., \& Boonyasana, P. (2017). Modelling Thailand tourism demand: a dual generalized maximum entropy estimator for panel data regression models. Thai Journal of Mathematics. Special Issue on Entropy in Econometrics, 67-78.

Cho, V. (2003). A comparison of three different approaches to tourist arrival forecasting. Tourism Management, 24, 323-330.

Claveria, O., \& Torra, S. (2014). Forecasting tourism demand to Catalonia: Neural networks vs. time series models. Economic Modelling, Elsevier, 36(C), 220-228.

Clements, M.P., \& Hendry, D.F. (1998). Forecasting economic time series, Cambridge, Cambridge University Press.

Constantino H A, Fernandes, P.O., \& Teixeira, J.P. (2016). Tourism demand modelling and forecasting with artificial neural network models: the Mozambique case study. Review of Applied Management Studies, 14(2), 113-24.

Coshall, J. T. (2005). A selection strategy for modelling UK tourism flows by air to European destinations. Tourism Economics, 11, 141-158. 
Coshall J. (2006). Time series analyses of UK outbound travel by Air. Journal of Travel Research, 44, 335-347.

Crouch, G. I. (1994). The study of international tourism demand: a review of practice. Journal of Travel Research, 33, 41-54.

Deng, M., \& Athanasopoulos, G. (2011). Modelling Australian domestic and international inbound travel: A spatial-temporal approach. Tourism Management, Vol. 32(5),10751084.

Dritsakis, N. (2004). Cointegration analysis of German and British tourism demand for Greece. Tourism Management, 25, 111-119.

Ghalehkhondabi I., Ardjmand, E, Young W. A., \& Weckman, G.R. (2019). A review of demand forecasting models and methodological developments within tourism and passenger transportation industry. Journal of Tourism Futures, 5(1), 75-93.

Goh, C., \& Law, R. (2002), Modelling and forecasting tourism demand for arrivals with stochastic no stationarity seasonality and intervention. Tourism Management, Vol. 23, pp. 499-510.

Goh, C., \& Law, R. (2011). The methodological progress of tourism demand forecasting: A review of related literature. Journal of Travel and Tourism Marketing, 28(3), 296-317.

Gunter, U., \& Onder, I. (2015). Forecasting international city tourism demand for Paris: Accuracy of uni- and multivariate models employing monthly data. Tourism Management, 46, 123-135.

Han, Z., Dubarry, R., \& Sinclair, M.T. (2006). Modelling US tourism demand for European destinations. Tourism Management, 27, 1-10.

Hanafiah, M. H. M., \& Harun, M. F. M. (2010). Tourism demand in Malaysia: A cross-sectional pool time-series analysis. International Journal of Trade. Economics and Finance, 1(1), pp. 80-83.

Karakitsiou, A. \& Mavrommati, A. (2017). Machine learning methods in tourism demand forecasting: Some evidence from Greece. MIBES Transactions, 11(1), pp. 92-105.

Karlaftis, M.G. (2010). Critical review and analysis of air-travel demand: forecasting models, computational models, software engineering, and advanced technologies in air transportation: Next Generation Applications, IGI Global, 71-87.

Khaidi, S. M., Abu1, N., \& Sarah, N.M. (2019). Tourism demand forecasting - A review on the variables and models. Journal of Physics: Conference Series, 1366.

Kirilenko, A.P., \& Stepchenkova, S. (2018). Tourism research from its inception to present day: Subject area, geography, and gender distributions, PLOS ONE 13(11): e0206820. https://doi.org/ 10.1371/journal.pone.0206820

Kolokontes, D.A., Kontogeorgos, A, Loizou, E, \& Chatzitheodoridis, F. (2018). Key-Sectors Attractiveness of the Greek Economy: An Input-Output Approach. Applied Econometrics and International Development, 18 (1), 35-54.

Kon, S.C., \& Turner, W.L. (2005). Neural network forecasting of tourism demand. Tourism Economics, 11, 301-328.

Kulendran, N., \& Shan, J. (2002). Forecasting China's monthly inbound travel demand. Journal of Travel and Tourism Marketing, 13, 5-19.

Kulendran, N. \& Wilson, K. (2000). Modelling business travel. Tourism Economics, 6, 47-59.

Lathiras, P., \& Siriopoulos, C. (1998). The demand for tourism to Greece: A Cointegration approach. Tourism Economics, 4(2), 171-185.

Li, G., Wong, K.F., Song, H. \& Witt, S.F. (2006). Tourism demand forecasting: A time varying parameter error correction model. Journal of Travel Research, 45, 175-185.

Lim, C., \& McAleer, M. (2001). Cointegration analysis of quarterly tourism demand by Hong Kong and Singapore for Australia. Applied Economics, 33, 1599-1619. 
Liang, Y.H. (2014). Forecasting models for Taiwanese tourism demand after allowance for Mainland China tourists visiting Taiwan. Computers \& Industrial Engineering, 74, $111-$ 119.

Liang, Z., Lim, C., Wenjun, X., \& Yuan, W. (2018). Modelling tourist flow association for tourism demand forecasting. Current Issues in Tourism, 21(8), 902-916.

Lim, C. (1997a). Review of international tourism demand models. Annals of Tourism Research, 24, 835-849.

Lim, C. (1997b). An econometric classification and review of international tourism demand models. Tourism Economics, 3, 69-81.

Lim, C. (1999). A Meta-analysis review of international tourism demand. Journal of Travel Research, 37, 273-84.

Lim, C., \& McAleer, M. (2001). Cointegration analysis of quarterly tourism demand by Hong Kong and Singapore for Australia. Applied Economics, 33, 1599-1619.

Maddala, G.S. (1987). Recent developments in the econometrics of panel data analysis. Transportation Research, 21, 303-326.

Maddala, G.S. (1991). To Pool or Not to Pool: That is the Question. Journal of Quantitative Economics, 7, 255-263.

Moro, S., Rita, P., \& Cortez, P. (2017). A text mining approach to analysing Annals literature. Annals of Tourism Research, 208-210.

Muhammad, A., \& Andrews, D. (2008). Determining Tourist Arrivals in Uganda: The Impact of Distance, Trade and Origin-Specific Factors. African Journal of Accounting, Economics, Finance and Banking Research, 2(2), 51-62.

Oilgenblick, L., \& Kirschenbaum, A. (2002). Tourism and immigration comparing alternative approaches. Annals of Tourism Research, 29(4), 1086-1100.

Önder, I. (2017). Forecasting tourism demand with Google trends: Accuracy comparison of countries versus cities. International Journal of Tourism Res, 19, 648-660. https://doi.org/10.1002/jtr.2137

Palmer, A., Montaño, J.J., \& Sesé, A. (2006). Designing an artificial neural network for forecasting tourism time-series. Tourism Management, 27, 781-790.

Rafidah, A., Shabri, A., Nurulhuda, A., \& Suhaila, Y. (2017). A wavelet support vector machine combination model for Singapore tourist arrival to Malaysia. IOP Conference Series: Materials Science and Engineering, 226(1), 012077.

Rosselló, J. (2001). Forecasting turning points in international visitor arrivals in the Balearic Islands. Tourism Economics, 7, 365-380.

Seetanah, B. (2006). Analysing transport capital as a determinant of tourist Arrival in a cointegration and error correction framework. International Review of Business Research Papers, 2, (2), 15-29.

Serra, J., Correia, A., \& Rodrigues, P.M.M. (2014). A comparative analysis of tourism destination demand in Portugal. Journal of Destination Marketing \& Management, 2, 221-227.

Sheldon, P.J., \& Var, T. (1985). Tourism forecasting: A review of empirical research. Journal of Forecasting, 4(2), 183-195.

Song, H., \& Jiang, Y. (2019). Dynamic pricing decisions by potential tourists under uncertainty: The effects of tourism advertising. Tourism Economics, 25(2), 213-234.

Song, H., Li, G., Witt, SF., \& Athanasopoulos, G. (2011). Forecasting tourist arrivals using time-varying parameter structural time series models. International Journal of Forecasting, 27(3), 855-869.

Song, H., \& Li, G. (2008). Tourism demand modelling and forecasting. Tourism Research, 29(2), 203-220. 
Song, H., \& Wong, K.F. (2003). Tourism demand modelling: a time-varying parameter approach. Journal of Travel Res. 42, 57-64.

Song, H., S. F. Witt, \& Li, G. (2003). Modelling and forecasting the demand for Thai tourism. Tourism Economics, 9, 363-87.

Song, H., \& Witt, S.F. (2000). Tourism demand modelling and forecasting: modern econometric approaches. Pergamon, Cambridge.

Surugiu, C., Leitão, N. C., \& Surugiu, M.R. (2011). A panel data modelling of international tourism demand: Evidence for Romania. Ekonomska istraživanja /Economic Research, 24(1), 134-145.

Tang, J., Sriboonchitta, S., \& Yuan, X. (2015). Forecasting inbound tourism demand to China using time series models and belief functions. Econometrics of Risk, Springer, Cham, 329-41.

Turner, L.W., \& Witt, S.F. (2001). Forecasting tourism using univariate and multivariate structural time series models. Tourism Economics, 7, 135-147.

Vanhove, N. (1980). Forecasting in tourism. Tourist Review, 35(3), 2-7.

Yang, X., Pan, P., Evans, J.A., \& Lv, B. (2015). Forecasting Chinese tourist volume with search engine data. Tourism Management, 46, 386-397.

Witt, S. F., \& Witt, C. A. (1995). Forecasting tourism demand: A review of empirical research. International Journal of Forecasting, 11, 447-475. 